\title{
A cost-effectiveness analysis of options for reducing pollution in Khayelitsha township, South Africa
}

\author{
EMUCHAPONDWA*
}

\begin{abstract}
Average levels of PM10 pollutants in Khayelitsha, a poor informal settlement nears Cape Town, are unusually high. The contributory factors are the burning of household waste, wood and used tyres; vehicular emissions; and dust. This paper gives guidance towards selecting interventions for reducing these pollutants. The options include planting windbreak trees; paving roads and walkways; using cleaner sources of energy; and supplying additional refuse skips. Based on cost data collected from relevant municipal departments and service providers, over a 20 -year planning horizon, the following are cost equivalents: planting between 419 and 936 windbreak trees; paving $6685 \mathrm{~m}^{2}$ of exposed areas; replacing between 451 and 870 wood-fired meat traders' braai (i.e. barbecue) sets with gas braais; and providing a $6 \mathrm{~m}^{3}$ refuse skip. On the basis of cost-effectiveness in reducing PM10 pollutants, this paper ranks the interventions as follows: (1) providing gas braai sets; (2) planting windbreak trees; (3) paving exposed areas; and (4) providing the refuse skip. Thus, providing gas braai sets to the meat traders in Khayelitsha will significantly reduce PM10 levels, but will also contribute to the sustained livelihoods of some of the poor households. However, planting windbreak trees may nevertheless be undertaken because of this option's linkage to climate change initiatives, which open up a wide range of potential funding opportunities.
\end{abstract}

Keywords: air pollution, cost-effectiveness, Khayelitsha, PM10, pollution control

Disciplines: Economics, Environmental studies, energy studies.

\section{Introduction}

Air pollution poses significant health-related challenges; particularly for poor people such as those living in South African informal settlements, whose health is already compromised by

School of Economics, University of Cape Town, Private Bag X3, Rondebosch 7701; Telephone: 021650 5242, Fax: 021650 2854; Email: edwin.muchapondwa@uct.ac.za. This work was conducted as part of the Khayelitsha Air Pollution Strategy (KAPS) project, a partnership between the City of Cape Town (CoCT), the Cape Peninsula University of Technology (CPUT) and the University of Cape Town (UCT), implemented by the Palmer Development Group (PDG) on behalf of the national Department of Environmental Affairs and Tourism (DEAT). The author is grateful for guidance from Ed Filby (CoCT), Tony Leiman (UCT), Elias Tukushe (CoCT), Keith Wiseman (CoCT) and the KAPS Steering Committee. The views expressed are those of the author and not necessarily those of the people and organisations mentioned above. Financial support from the Swedish International Development Cooperation Agency (SIDA) and DEAT is gratefully acknowledged. 
inadequate food, shelter ${ }^{1}$ and social services. The challenges emanate mainly from the high risk of contracting respiratory and cardiovascular illness, including chronic bronchitis and asthma. Illness has two detrimental effects on the poor: (i) it reduces the productivity of poor people, which in turn compromises their ability to generate income; and (ii) it increases the pressure on the meagre income of the poor, as they must pay for medical care - or receive home-based care from family members who would otherwise have been trying to earn an income. Thus, alongside other poverty-reduction initiatives that seek to increase the income levels of the poor, there is a need to prioritise initiatives that seek to reduce air pollution in areas where the poor people live; as such, the latter set of initiatives helps reduce the depth of poverty. This paper looks at a typical South African case study, in which the livelihoods of poor people can be enhanced through controlling air pollution - emanating partly from one of the limited livelihood options available to the poor.

Khayelitsha is a poor informal settlement, established near Cape Town in 1985 to cater for a growing black migrant population under apartheid. It currently has a population of about half a million and is among the largest townships of South Africa (Ndingaye 2005, Maverick $358 \mathrm{cc}$ 2006, Médecins Sans Frontières 2010). The Khayelitsha air pollution station monitors four major pollutants, namely PM10, sulphur dioxide $\left(\mathrm{SO}_{2}\right)$, ozone $\left(\mathrm{O}_{3}\right)$ and nitrogen dioxide $\left(\mathrm{NO}_{2}\right)$. The pollutant which has raised much concern is PM10, also called 'inhalable particulate matter'. The average PM10 levels (which have been monitored since 1999) are unusually high, at $48 \mu \mathrm{g} / \mathrm{m}^{3}$ for annual average concentrations, and are estimated to be $70 \%$ above those of Cape Town's central business district (CBD), which is nearby (KAPS 2008). Furthermore, the Khayelitsha PM10 levels frequently surpass the United Kingdom (UK) safety threshold levels of $50 \mu \mathrm{g} / \mathrm{m}^{3}$ (for 24-hour concentrations) and $40 \mu \mathrm{g} / \mathrm{m}^{3}$ (for annual average concentrations) adopted by the City of Cape Town Metropolitan Municipality, under which Khayelitsha falls. While there are no separate statistics for Khayelitsha, it is believed that the problem is significant because of the health impacts for PM10 exposure in Cape Town in 2002: 234 cardiovascular hospital admissions, 28806 incidences of chronic bronchitis and 217563 incidences of restricted activity days (Scorgie \& Watson 2004).

The Khayelitsha Air Pollution Strategy (KAPS) project was implemented to provide an understanding of the factors behind the high levels of PM10 observed. The project identified the factors that contribute to high PM10 levels in Khayelitsha as household waste burning, informal meat traders who burn wood for cooking fuel, waste tyre burning, vehicular emissions, and dust blown by wind from the unpaved roads and surfaces (KAPS 2008). The current study seeks to give guidance towards selecting the interventions for reducing PM10 levels in Khayelitsha.

The structure of the rest of the paper is as follows. Section 2 gives a background to the air pollution problem in Khayelitsha. Section 3 outlines the theoretical framework on which this study is based. Sections 4 and 5 determine the costs and effectiveness of a selection of the proposed interventions. In section 6 , there is a presentation and discussion of the cost-effectiveness analysis results; after which, section 7 concludes. 


\section{Background}

Air pollution generally refers to suspended particulate matter (PM), gaseous pollutants and odours. The major pollutant, which has raised much concern, is suspended PM. Types of suspended PM include diesel exhaust particles; coal fly ash; wood smoke; mineral dusts such as coal, asbestos, limestone and cement; metal dusts and fumes; acid mists (for example, sulphuric acid); and pesticide mists (Kjellström et al. 2006). The suspended PM includes the classes of the finer fraction, with median aerodynamic diameter of less than 10 microns (PM10), and the most hazardous fraction, with median aerodynamic diameter of less than 2.5 microns (PM2.5). Meteorological factors, such as wind speed and direction, are usually the strongest determinants of variations in suspended PM, along with topography and temperature inversions. In general, the effects of suspended PM can be divided into health, productivity and amenity categories (Voorhees et al. 2001). Long-term studies have documented increased cardiovascular and respiratory morbidity and mortality associated with exposure to PM10. Ecological studies of small areas based on census data, air pollution information and health events data (with adjustments for potential confounding factors, including socioeconomic status) also indicate that mortality increases with exposure to PM10 (Kjellström et al. 2006).

The brown haze and inversions above Khayelitsha have been points of concern and study for many years (for example, see Wicking-Baird et al. 1997 and Scorgie \& Watson 2004). However, over time the annual average PM10 concentrations and the number of episode days (days on which the threshold has been exceeded) in Khayelitsha have remained high, as shown in tables 1 and 2 below.

Table 1: Annual average concentrations $\left(\mu \mathrm{g} / \mathrm{m}^{3}\right)$ of PM10 for Khayelitsha (2000 to 2007)

\begin{tabular}{|l|l|l|l|l|l|l|l|}
\hline 2000 & 2001 & 2002 & 2003 & 2004 & 2005 & 2006 & 2007 \\
\hline No data & 51.64 & 50.28 & 50.83 & 42 & 45 & 50 & 45 \\
\hline
\end{tabular}

Source: Scorgie \& Watson (2004) and Benson (2008)

Table 2: Number of PM10 ep isode days recorded at Khayelitsha station (2000 to 2007)

\begin{tabular}{|l|l|l|l|l|l|l|l|}
\hline 2000 & 2001 & 2002 & 2003 & 2004 & 2005 & 2006 & 2007 \\
\hline 52 & 29 & 86 & 137 & 92 & 111 & 103 & 85 \\
\hline
\end{tabular}

Source: Scorgie \& Watson (2004) and Benson (2008)

The extent of the health effects of PM10 depends on actual exposure. Total daily exposure is determined by people's time and activity patterns, and it combines indoor and outdoor exposures. Young children and the elderly may travel less during the day than working adults, and their exposure may therefore correlate closely with air pollution levels in their homes. Children are particularly vulnerable to environmental toxicants because of their greater relative exposure and the effects on their growth and physiological development. Epidemiological analysis is needed to quantify the health impact in an exposed population (For examples, see Schwartz (1994), Wilson \& Suh (1997) and Moolgavkar (2000)). High concentrations of 
PM10 affect people with respiratory problems such as asthma, chronic bronchitis, coughing, wheezing and shortness of breath, as these particles can penetrate the lungs (KAPS 2008). Respiratory symptoms have been found to be the most commonly occurring health concern in two informal settlements in the Cape Metropolitan Area (Mathee \& Von Schirnding, 1996). In general, the major pollutants emitted by combustion have all been associated with increased respiratory and cardiovascular morbidity and mortality (Kjellström et al. 2006).

The variety of precursors to PM10 also leads to many different interventions. Interventions are often more sustainable if they address the driving forces behind the pollution at the community level, rather than attempting to deal with specific exposures at the individual level. In addition, effective methods for preventing exposure to PM10 may not exist at the individual level, and the only feasible individual-level intervention may be treating cases of illness. Examples of interventions to reduce PM10 include creating urban forests, covering unpaved roads and walkways, using alternative household burning energy sources, reducing garbage burning, lowering the sulphur content of diesel, and traffic demand management in urban areas (Kjellström et al. 2006).

For Khayelitsha, an intervention scenario committee was set up by the KAPS steering committee to investigate possible intervention strategies. The following interventions (aimed at reducing PM10 directly, or reducing its precursors) were suggested: planting of windbreak trees; covering of unpaved roads and walkways; promoting the use of alternative, cleaner-burning energy sources; providing additional refuse skips for household waste; establishing a tyre deposit-refund scheme; switching to Euro 2 vehicle emission standards; promoting the use of public transport; and mounting pollution avoidance and awareness educational campaigns (KAPS 2008). Given that we do not know how much each of the emission sources contributes to the overall PM10 level, we assume that each emission source contributes emissions significant enough to be a target of clean-up. If some emission sources contribute insignificant amounts to the overall PM10 level then interventions should not target the clean-up of such emission sources, as the scale of feasible clean-up would not reduce the overall PM10 level significantly. Ideally, one would want to implement all the independent feasible interventions, if that will result in lower PM10 levels and there are enough resources. However, implementation of each of the feasible interventions entails use of scarce resources; therefore, there is a need for triage.

It should be noted that some of the proposed interventions cannot be successfully implemented in constrained jurisdictions such as Khayelitsha, for several reasons. Firstly, establishing a tyre deposit-refund scheme ${ }^{2}$ and switching to Euro 2 standards $^{3}$ can only be effective if implemented

For viability, the scheme would need to guard against the importation of tyres from other areas. In any case, there are already national efforts by industry and government to establish a national waste tyre collection scheme. So far, the tyre industry has formed a Section 21 Company called the South African Tyre Recycling Process (SATRP) Company to manage the waste tyre collection process on its behalf, and the Department of Environmental Affairs and Tourism (DEAT) has published the 'Waste Tyre Regulation' for public comment; and SATRP aims to operate a sustainable South African waste tyre collection process and make it available to all users of waste tyres a year after promulgation of the Waste Tyre Regulation by DEAT. More information is available at http://www.rubbersa.com/index.htm.

For viability, the switch would need to be implemented nationally; otherwise, vehicles from other jurisdictions without such standards cannot be stopped from entering Khayelitsha. Currently, all vehicles in South Africa should comply with the Euro 1 emissions standard; and it has already been estimated that a switch to Euro 2, a stricter emission standard, would result in $5 \%$ to $10 \%$ improvement per annum in national air pollution from vehicular sources. 
at national level. Secondly, promoting the use of public transport in Khayelitsha is not feasible given that there is no excess capacity on public transport in Khayelitsha; and the City of Cape Town is not directly in charge of public transportation, as the railway service is under a national authority, the bus service is under a provincial authority, and the minibuses are privately owned. Thirdly, a pollution avoidance and awareness educational campaign should not be seen as independent from the other interventions, as they all need to come co-packaged with educational campaigns.

Thus, the potentially feasible measures for reducing PM10 in Khayelitsha include planting windbreak trees; covering unpaved roads and walkways; promoting the use of alternative, cleaner-burning energy sources; and providing additional refuse skips for waste material.

\section{Theoretical framework}

The most common method of evaluating air pollution control interventions in which costs and benefits can be valued in monetary terms is cost-benefit analysis (CBA). For examples of costbenefit analysis, see Krupnick \& Portney (1991), McPherson et al. (1999), Voorhees et al. (2001) and Leiman et al (2007). On one hand, the costs associated with an intervention are usually easily discernible. Costs associated with implementing an intervention may potentially be incurred by three economic sectors, namely the private sector; society at large; and the governmental regulatory authority (Voorhees et al. 2001). These costs include direct and indirect costs, where direct costs comprise capital costs (expenditure for facilities, equipment, etc) and operating costs (implementation costs, maintenance costs, materials costs, equipment leasing, parts and supplies, direct labour, fuel and power, services provided by private contractors, and research and development).

Indirect costs include the macroeconomic impacts due to shifts in economic activity between industries, including changes in the distribution of labour, capital, and other production factors within the economy, and changes in the distribution of goods and services (Voorhees et al. 2001). It is mostly because of the indirect costs that reliance on the engineering costs of an intervention has been criticised, because capital and operating expenses alone do not account for the dynamic and general equilibrium impacts of regulation.

On the other hand, the benefits of an intervention are usually not that obvious, and in most cases are not readily perceptible in monetary terms. The basic components of benefits are the health, productive and amenity effects that will be avoided. In addition, it is worth noting that some interventions have a broader value; for example, tree planting has amenity values beyond its effect on air quality.

The process of estimating the benefits of an air pollution control intervention has two steps: namely finding the physical impacts, and then monetising them. The physical impacts of air pollution control interventions are found by (1) estimating the dose-response function, (2) multiplying the slope of the dose-response function by the exposed population and (3) multiplying the product by the estimated change in air quality. ${ }^{4}$ Three valuation approaches have 
been used in the literature to monetize the benefits associated with interventions: (1) market valuation of physical effects, (2) stated preference methods, and (3) revealed preference methods.

The effects of air pollution that are most amenable to market valuation include human health effects and productivity effects (for example, work output, crop yield, fishing yield, damage to industrial equipment and soiling). Amenity effects - including visibility, odour and noise - are the most amenable to surrogate market valuation using either contingent valuation or hedonic pricing (and it is worth stressing that the feedback from the KAPS survey indicated that amenity effects dominated perceptions of the problem). However, ecosystem health typically does not have market value. Likewise, natural ecological impacts which may occur cannot be valued without relevant dose-response functions (Voorhees et al. 2001).

Given the varied nature of the possible interventions, it may not always be possible to catalogue and monetise the returns associated with each intervention. Furthermore, a full cost-benefit analysis may not be necessary; especially when the problem is to determine how best to comply with a requirement to reduce PM10. In such cases, one may only need to compare the interventions on the basis of the resources required to implement each intervention, up to the point yielding a unit reduction in PM10. Such an analysis would essentially be a costeffectiveness analysis - a widely-used alternative to cost-benefit analysis, especially in areas such as health and defence policy.

Cost-effectiveness analysis is a systematic method for finding the lowest-cost means of accomplishing an objective. More broadly, cost-effectiveness analysis compares costs and the effects of an intervention to assess whether the intervention is worthwhile on economic grounds. In particular, it compares mutually exclusive alternatives in terms of their costs and a single, quantified (but not monetised) effectiveness measure (Boardman et al. 2006). Cost-effectiveness analysis is often used in cases for which a full cost-benefit analysis would be inappropriate; for example, where the problem is to determine how best to comply with a legal requirement. Note that in general the cost-effectiveness analysis procedure does not produce an efficient allocation, because the predetermined objective may not be efficient; all efficient policies are cost-effective, but not all cost-effective policies are efficient (Perman et al. 2003). Nonetheless, a good costeffectiveness analysis can be more useful than CBA.

Though cost-effectiveness analysis does not monetise benefits, it does measure two other metrics: costs in monetary terms; and effectiveness of an intervention, which may be measured in, say, kilograms of PM10 reduced. The ratio of the two measures is what is used as a basis for ranking alternative interventions. (Of course, an appropriate basis from which to compute the effects and costs of alternatives must be chosen.) Even though the ratio can be expressed in two ways, namely cost/effectiveness and effectiveness/cost, the most commonly-used approach is the cost-effectiveness ratio, computed by dividing the costs of an alternative by the measure of its effectiveness. Thus, cost-effectiveness analysis involves computing cost-effectiveness ratios in order to choose policies or interventions that promote efficiency, especially where the chosen predetermined objective is itself efficient. Costs and effectiveness are always measured incrementally. 
Examples of cost-effectiveness analysis for assessing air-quality policy include studies carried out in Jakarta, Kathmandu, Manila and Mumbai, under the World Bank's Urban Air Quality Management Strategy in Asia (Grønskei et al. 1996a, 1996b; Larssen et al. 1996a, 1996b; Shah et al. 1997 cited in Kjellström et al. 2006). In each city, an emissions inventory was established and rudimentary dispersion modelling was carried out. Various measures for reducing PM10 and mitigating health impacts were examined in terms of reductions in tons of PM10 emitted, cost of implementation, time frame for implementation, and health benefits and their associated cost savings. Some of the abatement measures that have been implemented include introducing unleaded gasoline, tightening standards, introducing low-smoke lubricants for vehicles with twostroke engines, implementing inspections of vehicle exhaust emissions to address the problem of gross polluters, and reducing garbage burning (Kjellström et al. 2006). For other examples of cost-effectiveness analyses, see O’Ryan (1993), McPherson et al. (1998), Nowak et al. (1998), US EPA (2006) and Escobedo et al. (2008).

Our intention is to conduct a cost-effectiveness analysis of a selection of the proposed interventions for reducing PM10 in Khayelitsha. In order to do this, we need to understand only the costs of implementing each intervention and the associated impact of the intervention.

\section{Ascertaining the costs of interventions}

In this section we ascertain the costs of each of the selected interventions. In general, the costs are direct and indirect, and include intangible costs. Some costs will be immediate while others will be spread over time. Immediate costs are usually associated with implementing or mounting the intervention, while future costs could be the necessary maintenance and operating costs to guarantee the standard of the intervention's impact.

\subsection{Planting of hardy windbreak trees}

Khayelitsha lies in the Cape Flats area. On the whole, the natural vegetation on the Cape Flats is slow-growing shrubs and bushes, sparse grasses or reeds and geophytes (bulbs) (Burgess 2008). The prevalent use of firewood on the Cape Flats also contributes to the decrease in vegetation that previously helped in soil stabilisation. The geophysical characteristics of the Cape Flats predispose the area to air-quality problems. The area is windy, flat and sandy, meaning that dust is easily picked up by the wind. It was estimated that in 2006 , roughly $70 \%$ of the Khayelitsha area was not covered by vegetation and was therefore a source of dust. This estimate is derived from aerial photographs taken at the time; there has been development in the last four years, and the open area has expanded. Windblown dust clogs drains, exacerbating flooding. This kind of flooding gives the dust cycle further impetus (Schoeman 2008).

It is believed that windblown dust contributes significantly to PM10 in Khayelitsha. This is because Khayelitsha is near the coast; the sand contains particles that are very fine and blown about easily; there are very few mature trees and large built structures to act as windbreaks; there are many exposed areas that are not stabilised by plant material, in areas that are undeveloped or have natural vegetation; and there are many un-surfaced informal footpaths in areas between residences and buildings and on undeveloped land. Also, as the informal footpaths take higher pedestrian traffic, the exposed sandy area becomes larger and larger, leaving more surface area open for wind erosion. Many areas that have been developed or surfaced are adjacent to undeveloped land and one often finds that the sand blows in from these adjacent sites, covering 
the new surface. Windblown sand is transported inland from areas closer to the sea (beyond Lookout Hill) (Schoeman 2008). Thus, the set of interventions requires integrated programmes for stabilising soil.

The first proposed intervention would be planting hardy trees to serve as windbreaks and dustdeposition facilitators. ${ }^{5}$ In general there are no large indigenous trees found naturally on the Cape Flats, so planting trees suitable for the Khayelitsha area and able to meet the needs of an urban environment is particularly challenging. ${ }^{6}$ In most urban environments trees are used to create windbreaks; delineate edges of spaces and places; provide shade to pedestrians; provide wind shelter for housing, play areas and sports fields; increase biodiversity; and generate oxygen to reduce carbon dioxide poisoning caused by carbon-based fuel systems and cars. It is very difficult to grow trees in Khayelitsha and there are relatively few historical precedents to call upon, since Khayelitsha has only existed for 22 years (Burgess 2008).

Though there are shrubs and plants that are well adapted to these conditions, we assume that this intervention would use trees. Trees planted in Khayelitsha are very often stunted due to a number of factors such as: (i) Insufficient wind protection by buildings and walls. If necessary, trees can be protected with shade netting or other material on the wind side; (ii) Exposure to harsh conditions. Nursery trees grown in protected environments take a sudden 'knock' when planted and exposed to harsh conditions; it is better to plant trees that have been 'hardened off; (iii) Lack of regular maintenance. There is a need for ongoing maintenance every year, such as regular feeding of the tree with fertiliser and compost to ensure that the tree gets sufficient nutrients from the soil for good growth; and (iv) Lack of adequate regular precipitation. There is a need for optimal, ongoing watering of the growing tree (Schoeman 2008).

For the tree-planting programme to be effective in reducing dust (and consequently PM10), there must be enough suitable land for an adequate number of trees to be planted. The location of planting also matters significantly if the trees are to be effective wind barriers (or dustpreventive agents). If there is inadequate public open space for use in the tree-planting programme, a possible alternative would be to plant the trees along the roads. (A problem in this regard is the situation of drainage and water pipes, which are usually laid alongside roads. Also, one would be restricted to roads that are not earmarked for future expansion.)

There are several tree species options suitable for Khayelitsha, for example Beefwood (casuarina), ficus rubiginosa, populous simonii and Kareeboom (rhus spp.). Although an alien species, casuarina is a favourite because of its quick maturation time. It is also not threatened by firewood users as it is not a good source of fuel. At the same time, it captures dust particles rather well. Another more typical (though less robust) tree is the ficus rubiginosa, which could also cope well in Khayelitsha but would need more help than casuarinas do. The planting costs of any tree variety chosen will largely be made up of costs for the tree, cage, water and maintenance. ${ }^{7}$ Tables 3 and

Certain types of grasses could be considered, as could other options such as road-tarring and laying hardtop on open spaces. For planting, one would have to look for plants that sustain themselves without excessive irrigation. (Acacia cyclops) trees, both invasive Australian acacias. Planting of Austrialian acacias is now illegal. planting will assist in breaking down the force of the wind in the area on the sheltered side of such windbreaks. 
4 below gives the approximate tree costs (excluding valued added tax) for casuarina and ficus rubiginosa.

Table 3: Costs of a casuarina tree-planting intervention

\begin{tabular}{|l|l|}
\hline Description & Amount (R) \\
\hline Cost of a tree, cage, water and two years' maintenance & 2000 \\
\hline Total & 2000 \\
\hline
\end{tabular}

Source: City Parks Department

Table 4: Costs of a Ficus rubiginosa tree-planting intervention

\begin{tabular}{|l|l|}
\hline Description & Amount (R) \\
\hline Cost of a 100-litre tree & 850 \\
\hline Excavation of tree hole & 350 \\
\hline Compost and soil preparation per tree & 1260 \\
\hline Cage to protect tree during growth & 2000 \\
\hline Stone mulch around the base of the tree & 50 \\
\hline Geofabric around the base of the tree & 50 \\
\hline Drip irrigation fittings per tree & 100 \\
\hline Total & 4660 \\
\hline
\end{tabular}

Source: Schoeman (2008)

\subsection{Covering of unpaved roads and walkways}

Apart from planting exposed areas, some of the ways that can be used to reduce PM10 pollution include paving exposed walkways and roads, and adding windbreaks in the form of buildings, walls and other structures. It is important to note that the City of Cape Town has already embarked on a paving and tree-planting project along Spine Road in Khayelitsha (see Figure 1). The Klipfontein Non-Motorised Transport (NMT) Route is a City of Cape Town initiative, and is intended eventually to provide a continuous link from Khayelitsha to the Cape Town CBD. Sections of the NMT route have been in development since 2007. The aim of the initial phase of

Without tight planting, effectiveness is lowered. But there is a negative aspect: the association of tightlyplanted trees with crime is a problem.

To completely ascertain the costs and effectiveness of the intervention of planting hardy windbreak trees, ideally one would need to know the number of trees that constitute an effective windbreak in Khayelitsha, the associated cost, and the associated reduction in PM10. 
the project is to service a three-kilometre stretch of Spine Road. So far only a kilometre straddling Wards 94 and 97 has been serviced. The major concerns of the NMT project are safety, accessibility, and beautification. Thus, the main stakeholders are envisaged to be pedestrians, cyclists, wheelchairs, etc (Tukushe 2008).

Under the NMT project, adjacent roadways and informal walkways are paved. Trees are planted about 5 metres apart and caged to guard against vandalism. Each tree is fitted with a drip irrigation system. Refuse bins, signage and public benches are also provided on these surfaces. The City Parks department immediately takes over the planted trees for maintenance. Ficus rubiginosa and populous simonii have been planted, but they may be adversely affected by the harsh climatic and sandy soil conditions (Tukushe 2008).

\section{Figure 1: NMT project combining paving and tree planting in Khayelitsha}

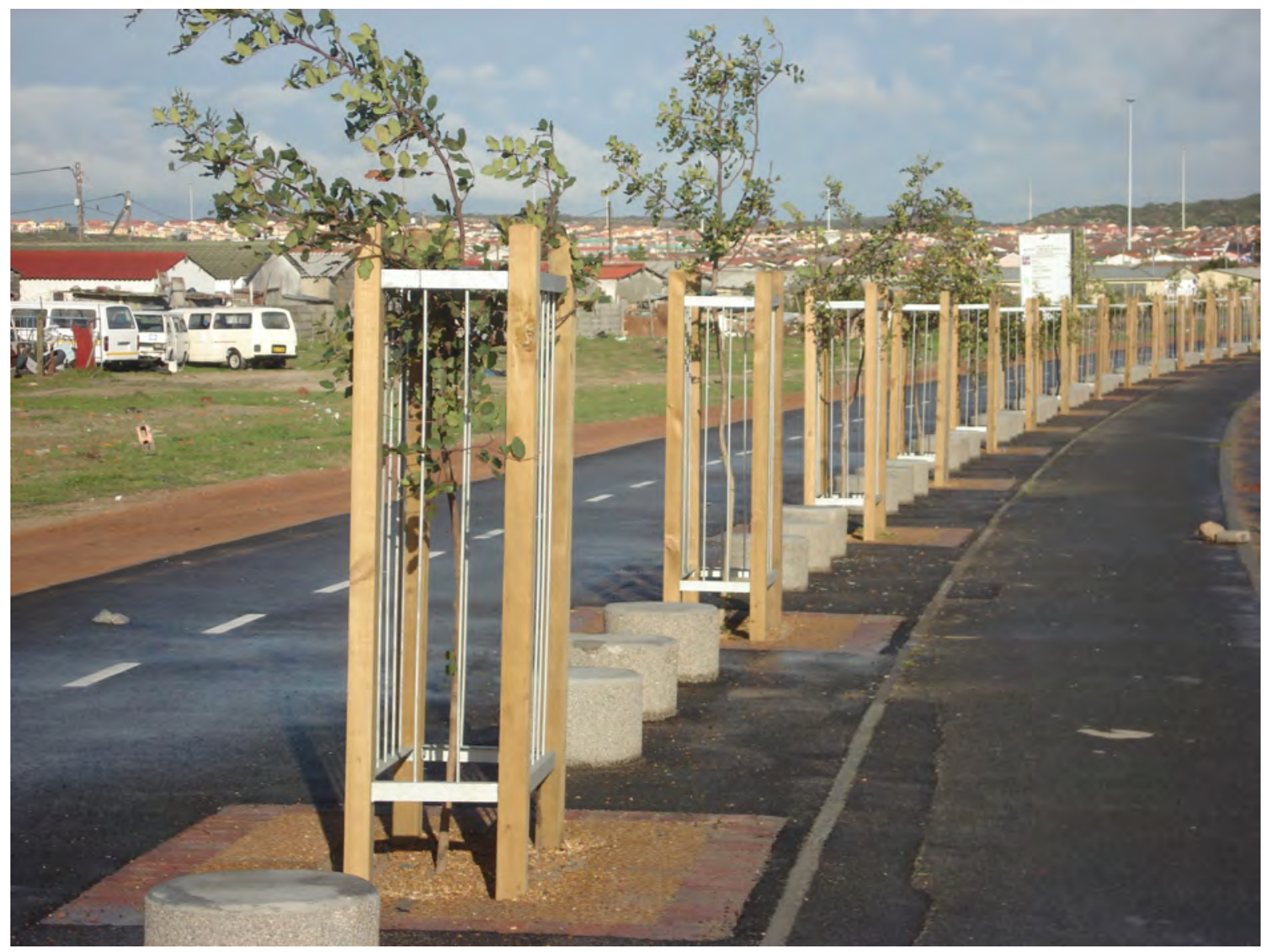

Source: Edwin Muchapondwa

Even though the primary goal of the NMT project is not air-quality management, it makes a contribution to PM10 reduction nevertheless. In percentage terms, only a small proportion of the exposed areas in Khayelitsha have been covered by the NMT project. However, the NMT project will also assist with the adjacent roadways, where the road and stormwater catchpits should become less clogged with sand. The area that has been covered by the NMT project is approximately $14330 \mathrm{~m}^{2}$. The estimated paving cost based on final certificate costs is $\mathrm{R} 280 / \mathrm{m}^{2}$ excluding VAT (Schoeman 2008). Under the proposed KAPS intervention there would be 
surface covering of unpaved areas and walkways in the area surrounding the Air Quality monitoring site on Lansdowne Road in Khayelitsha. ${ }^{9}$

Table 5: Costs of covering unpaved areas and walkways

\begin{tabular}{|l|l|}
\hline Description & Amount (R) \\
\hline Cost of paving $1 \mathrm{~m}^{2}$ (includes site clearance, earthworks, surfacing, etc) & 280 \\
\hline Total & 280 \\
\hline
\end{tabular}

Source: Schoeman (2008)

\subsection{Promoting the use of alternative, cleaner-burning energy sources}

The KAPS surveys captured heavy reliance on wood by informal meat traders. Wood is used extensively by informal traders as the main fuel for grilling meat. The wood is burnt for about 12 hours every day. There is extensive use of green wood despite all involved knowing that it emits more smoke than seasoned wood. The reasons for its continued use are that green wood prolongs the life of a fire; other wood is scarce during winter; and there is a belief that burning green wood keeps flies at bay. In addition, the burning of animal fats associated with grilling meat makes the resulting PM10 pollution very serious. Most of the meat traders buy from local wood traders, who collect from the bushes as far as $5 \mathrm{~km}$ away.

This intervention would involve replacing the wood used by the informal meat traders at the business centres with cleaner-burning energy sources. ${ }^{10}$ Possible alternatives include charcoal and gas. ${ }^{11}$ For various practical reasons, gas is the option chosen for this intervention. The meat traders would need to acquire the gas braais and cylinders. The surface area of the wood braai used currently is about $0.54 \mathrm{~m}^{2}$. The equivalent surface area can be obtained from a 4-burner gas braai. Figures 2 and 3 show typical wood and gas braais, with equivalent surface areas.

It should be pointed out that the prime motivation for focusing on the area in the vicinity of the monitoring station should not be to achieve lower pollution readings by reducing dust only in the neighbourhood of the monitoring equipment.

A slight complication with this intervention is that it requires commitment by individuals to cooperate in reducing or eliminating wood usage. Given that this intervention targets businesspeople, it must make business sense for the informal traders to switch to cleaner-burning energy sources willingly. It is possible that the costs for the alternative sources could be prohibitive. If this is the case, effective implementation of this intervention would require targeted subsidies. The intervention would also need to recognise the existence of a wellestablished wood-trading industry which supplies wood to meat traders. Any switch to alternative energy sources may have a negative impact on the livelihood of the wood traders.

Another alternative is improved wood-burning technology. An on-going initiative, the SADC Programme for Basic Energy \& Conservation (ProBEC), being implemented by the German Agency for Technical Cooperation (GTZ), promotes efficient biomass energy technologies through the use of a 'Rocket' stove. However, as currently designed the 'Rocket' stove is not suited to the 'braai-ing' application (Mrubata et al. 2008). 
Figure 2: The base section of the type of wood braai currently being used by meat traders in Khayelitsha

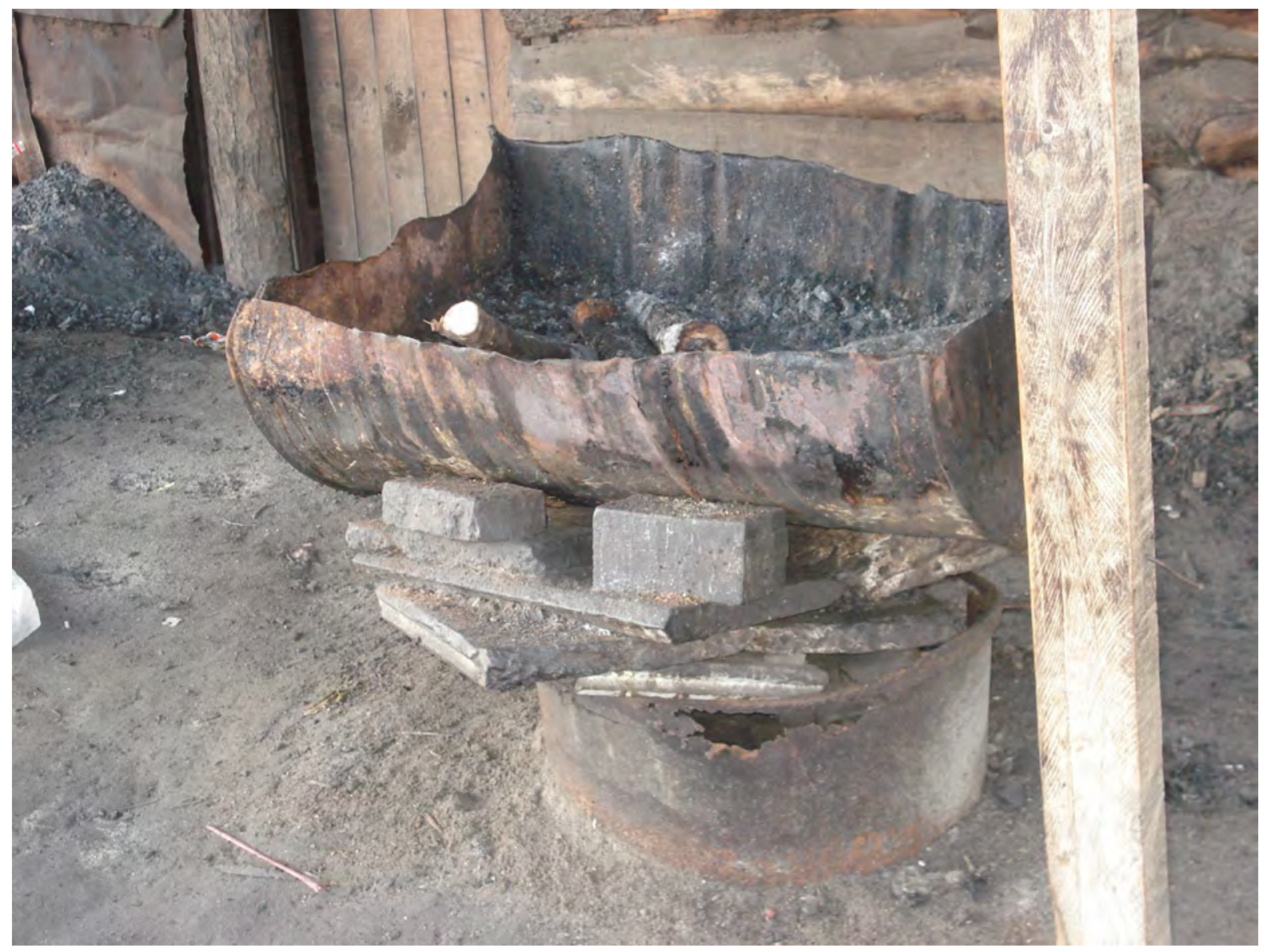

Source: Edwin Muchapondwa 
Figure 3: A 4-burner gas braai which could replace wood braais in Khayelitsha

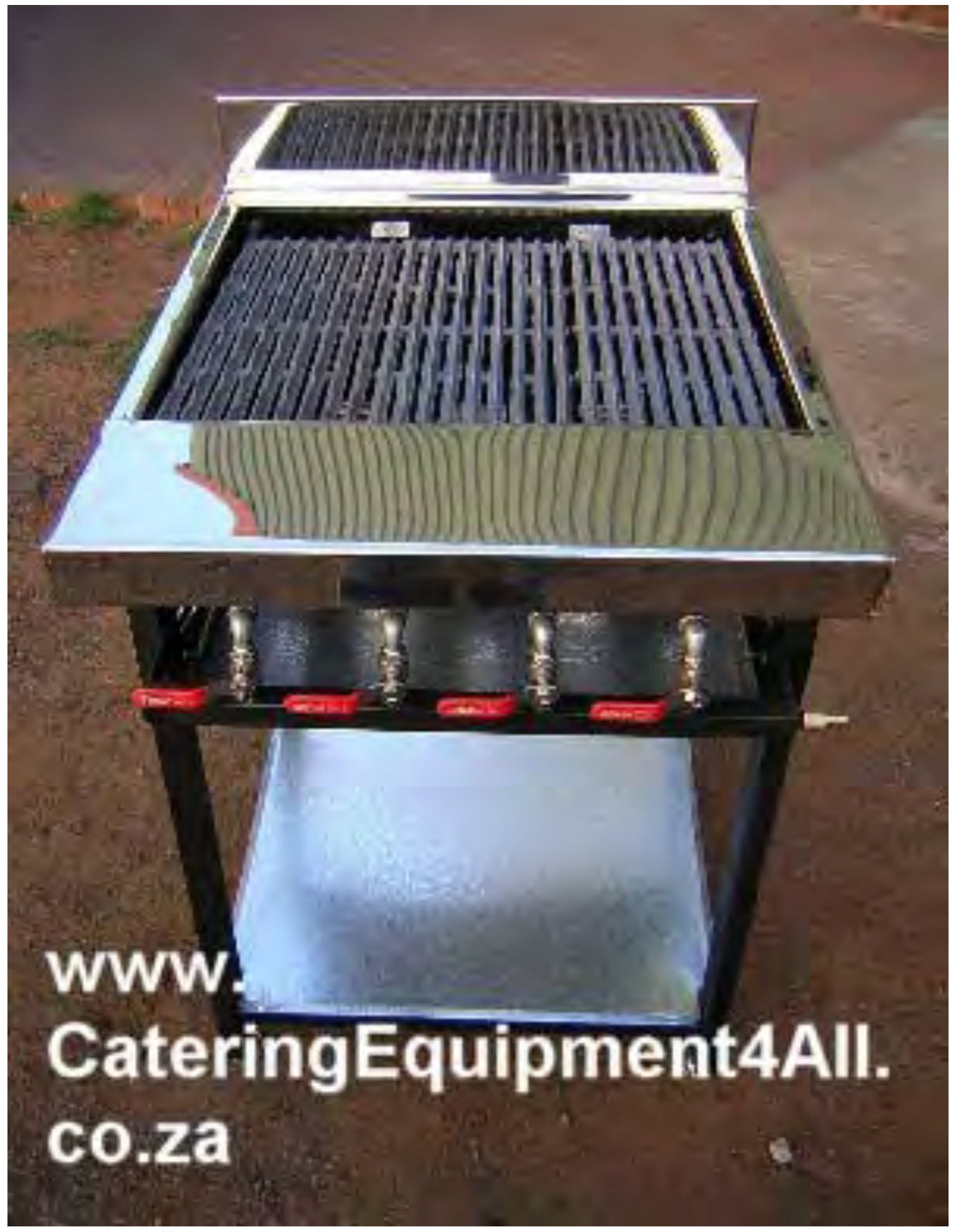

Source: http://www.cateringequipment4all.co.za/braai.html

A 4-burner gas braai costs between R2 000 and R4 000, depending on quality. A gas cylinder of any size can be obtained for a deposit of R150. The traders would then need to refill the cylinders with a quantity of gas $-9 \mathrm{~kg}, 14 \mathrm{~kg}, 19 \mathrm{~kg}$ or $48 \mathrm{~kg}$. It is estimated that using a 4-burner gas braai for 12 hours of a day would burn $3 \mathrm{~kg}$ of gas, or $90 \mathrm{~kg}$ per month. As can be calculated 
from the table below, the lowest cost of gas is about R16.12 per kg (excluding VAT). At that price, the cost of $90 \mathrm{~kg}$ of gas (i.e. a month's supply) would be about R1 450 .

Table 6: Price of gas (excluding value added tax)

\begin{tabular}{|l|l|l|l|}
\hline $9 \mathrm{~kg}$ & $14 \mathrm{~kg}$ & $19 \mathrm{~kg}$ & $48 \mathrm{~kg}$ \\
\hline R147.69 & R226.38 & R307.23 & R773.76 \\
\hline
\end{tabular}

Source: African Oxygen Limited (Afrox)

The switch from wood braais to gas braais would therefore cost between R2 150 and R4 150 (including a cylinder deposit of R150) initially and R1 450 every month, i.e. between R3 600 and R5 600 for the initial launch. The meat traders who switch would avoid the costs associated with wood procurement. KAPS (2008) reports that they use an average of two-and-a-half trolleys of wood a day. With a trolley of wood costing about R40, each meat trader would avoid wood expenses of about R100 per day (or R3 000 per month). It therefore seems that besides factors such as easy access, safety and security, gas is a cheaper alternative in the long run, as the monthly operating costs of gas braais are lower than those of wood braais.

The question is, why have they not changed so far? The inertia may be due to the setup costs, or the inconvenience of getting gas refills. Also, the figures above tend towards the conservative, as there might be additional transport costs associated with securing the gas equipment and the monthly gas supplies. The traders might also incur costs associated with storage, given that unlike wood braais, which are usually left lying outside - gas braai equipment will need special storage facilities for safety and security.

If the meat traders can be motivated by the lower operating costs of gas braais, the advisable implementation for this intervention would be for the City to provide gas braais and cylinders for all traceable informal meat traders. The associated cost of the intervention would therefore only include the cost of the gas braai equipment as shown in table 7 below.

Table 7: Costs of the capital equipment for switching from wood braais to gas braais

\begin{tabular}{|l|l|}
\hline Description & Amount (R) \\
\hline 4-burner gas braai & 2000 to 4000 \\
\hline Gas cylinder deposit & 150 \\
\hline Total & 2150 to 4150 \\
\hline
\end{tabular}

Source: Quotations from suppliers

4.4 Providing additional refuse skips for household waste 
The City's policy is to provide lockable shipping containers which are cleared twice a week. Currently, the Solid Waste Department supplies one $6 \mathrm{~m}$ shipping container per 400 dwellings (Horn 2008) (see Figure 4). Households in all the informal settlements are given free black bags in which they accumulate their waste before off-loading it at the container.

Figure 4: A lockable shipping container currently meant to be used by 400 dwellings

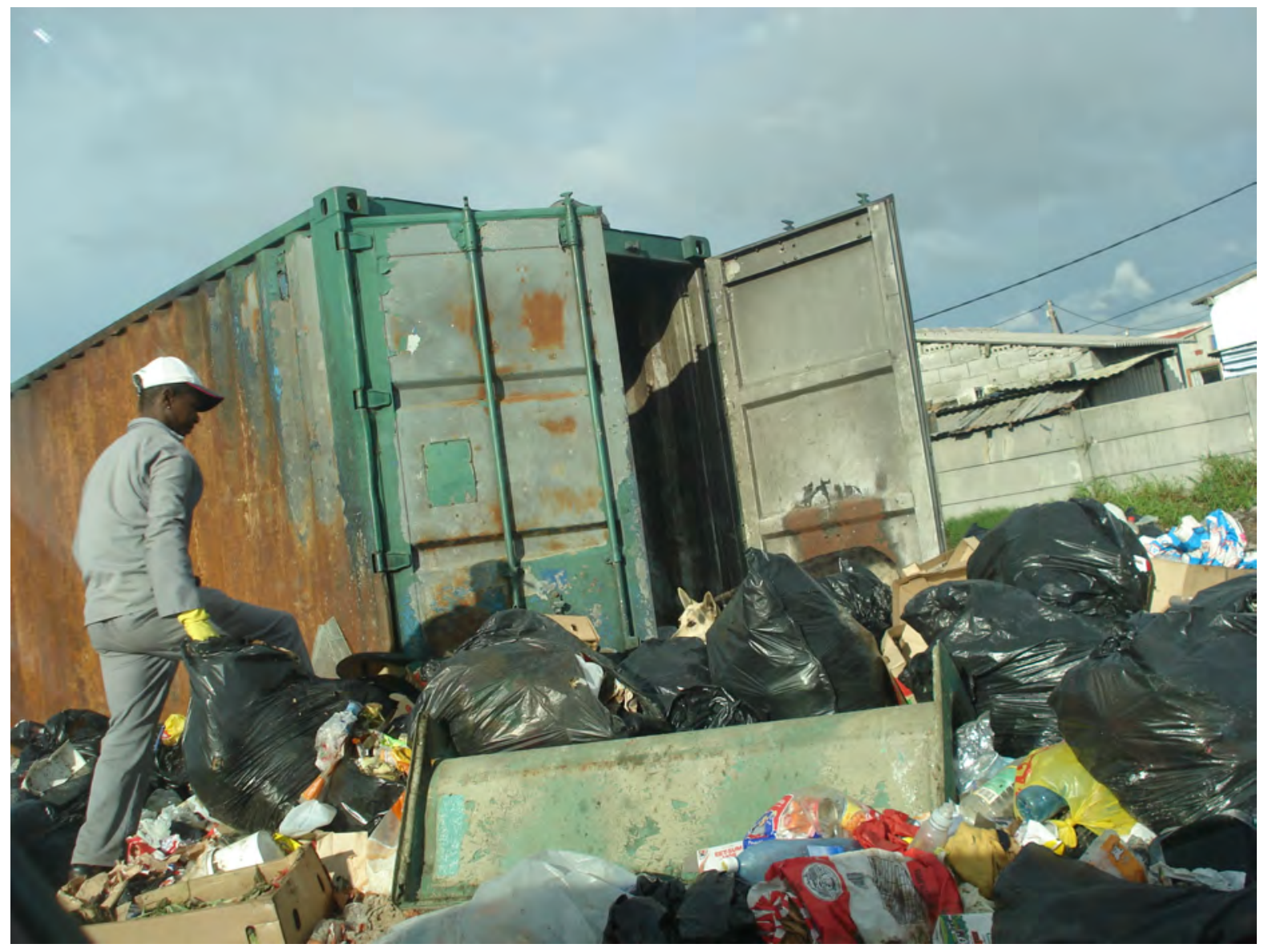

Source: Edwin Muchapondwa

The data on waste management service delivery in Table 8 below suggests that $89.97 \%$ of households had their waste removed by the local authority at least once a week in 2005/2006. The remaining households' waste could fall into any of the other categories: removed less often than once a week, communal refuse dump, own refuse dump, or no rubbish removal. In some informal settlements, community servicing is arranged on a rotational basis as a way to involve communities and create incomes for them. ${ }^{12}$ Due to a recent shortage of shipping containers a

The Solid Waste Department strongly asserts that all households in Khayelitsha are serviced at least once per week. The informal settlements unit carries out surveys once every two weeks. The Solid Waste Department provides a service if they become aware of newcomers who would not be receiving a service. In cases where there are service delivery problems the councillor is supposed to bring this to the attention of the sub-council or the call centre. It is likely that at times some people simply miss the waste collection, since it is scheduled for once a week. Sometimes mischievous action leads to the burning of waste, and this is likely to happen from

TD, 6(2), December 2010, pp. 333-358. 
very limited number of skips - each with a carrying capacity of $6 \mathrm{~m}^{3}$, or 72 black bags - were temporarily rolled out, and will be replaced when containers become available (Horn 2008).

Table 8: Proportion of refuse removed by local authority at least once a week: 2005/2006

\begin{tabular}{|l|l|}
\hline Khayelitsha Wards in KAPS survey area & Proportion of weekly refuse removed (\%) \\
\hline Ward 87 & 99.64 \\
\hline Ward 88 & 77.03 \\
\hline Ward 89 & 98.55 \\
\hline Ward 90 & 88.15 \\
\hline Ward 91 & 86.47 \\
\hline Ward 92 & Not available \\
\hline Simple Average & 89.97 \\
\hline
\end{tabular}

Source: CoCT (2005a, 2005b, 2006a, 2006b, 2006c, 2006d)

The current proposed intervention targets PM10 from the burning of household waste. The contention is that refuse removal is inadequate, leading people to resort to burning waste. In this intervention the primary motive is to serve those who are currently not being served by the current refuse removal infrastructure.13 This intervention would entail the provision of additional refuse skips to be positioned at points where burning of waste has been identified, in order to eliminate the need to burn the levels of burnt waste observed currently.14, 15 The

time to time; but not frequently. There is therefore a need for enhanced communication and education. There might be a need to find new ways of educating the communities, e.g. community theatres (Coetzee 2008).

Depending on the structuring of refuse removals, it might also be the case that some people merely miss the current refuse removal routines which are otherwise capable of accommodating them. The times, days and locations of refuse removals may simply be inconvenient for some households. The extent to which burning of waste is a problem should be identifiable from the data on its contribution to PM10 levels in Khayelitsha. However, detailed current information regarding the exact extent of informal waste burning and the likely extent of emissions is not available.

This intervention would need to be implemented along with a targeted public awareness and educational campaign. Furthermore, the onus would be on the City Solid Waste Management Department to ensure that the additional refuse skips are well managed, to avoid creating other environmental health problems - there is a risk that the additional skips will simply spill over and create additional environmental and health problems as animals scavenge on the waste.

Even though the provision of additional refuse skips has been suggested as a possible intervention, the Solid Waste Department does not recommend such an action as an effective way of curbing PM10 levels. Given the high level of waste removals, it is not believed that additional refuse skips would add much to the aggregate amount of refuse collected. In the Solid Waste Department's view, the provision of additional refuse skips constitutes an unnecessary cost, given that one would need to either invest in the additional skips as well as additional vehicles to collect those skips, or contract private waste management service providers to do so. Given that the City itself does not currently have the necessary equipment, especially the vehicles, this 
Solid Waste Department estimates that servicing a skip costs roughly R900 per lift, and normally two lifts are done per week. This is a cost of R93 600 per skip per year. Table 9 summarises the costs of the current intervention and those of the other three interventions discussed earlier.

Table 9: Costs of the PM10 reduction interventions

\begin{tabular}{|l|l|}
\hline Intervention & Costs \\
\hline Planting of windbreak trees & R2 000 to R4 460/tree \\
\hline Covering of unpaved roads and walkways & R280/m² paved \\
\hline Promoting the use of cleaner-burning energy sources & R2 150 to R4 150/gas braai \\
\hline Providing additional refuse skips for household waste & R900/skip lift; 2 lifts/week \\
\hline
\end{tabular}

\section{Ascertaining the effectiveness of interventions}

Ascertaining the impact of an intervention is not a trivial task, as it does not only depend on emissions rates. Exposure to the emissions is what may really matter. But exposure to emissions is also intricately influenced by other factors such as height of release of pollutants; proximity of source to areas with high human exposure potential; duration and frequency of emissions; and climatic variables such as inversions. For instance, Scorgie \& Watson (2004) report that over the Cape coast a persistent low-level subsidence inversion is evident, with its base at approximately 1 $\mathrm{km}$; in addition, the height and persistence of elevated inversions vary with latitudinal and longitudinal position. Khayelitsha is also known to experience low level inversions, a few metres above ground, which trap air pollution. Furthermore, diurnal variations in the wind field and in atmospheric mixing depths - and hence in pollution accumulation and dispersion potentials result in significant daily variations in air pollutant concentrations, even on days when there is little difference in emission rates (Scorgie \& Watson 2004).

To judge the impact of interventions, we start from the premise that PM10 has known impacts on health outcomes, productivity and amenity values. Such information is readily available from the relevant dose-response functions. Therefore, instead of focusing on the impact of interventions in terms of how the constituents of PM10 (i.e. dust, mist, smoke, etc) from the various interventions affect health outcomes, productivity and amenity values, we focus on the extent to which the interventions affect PM10 levels. It must be noted that we are focusing on

intervention would also mean a heavy administrative burden, because implementing the intervention would require the tendering and contracting of private waste management service providers. Therefore, the Solid Waste Department is of the view that additional refuse skips should only be considered as an emergency service. In fact, the usual practice is to provide skips as an emergency until regular integrated service can be provided (Coetzee 2008). This paper takes the view that the provision of additional refuse skips should not be dismissed independently of other interventions. The views of the Solid Waste Department will be accounted for appropriately under costs and effectiveness of the additional refuse skips.

TD, 6(2), December 2010, pp. 333-358. 
the primary PM10 emissions. ${ }^{16}$ With this information, it is then feasible to compare the impacts of the various interventions in terms of a plausible common denominator, i.e. their effect on PM10 levels (or PM10 emission rates).

Ordinarily, the effect of each intervention on PM10 levels could be obtained by using the relevant emissions factors for fuel usage changes and changes in direct PM10 emissions in each intervention. Emission factors are given in $\mathrm{kg}$ of PM10 emitted as a result of a unit of fuel burned. Using the United States Environmental Protection Agency (US EPA) database, Scorgie and Watson (2004) derived the following PM10 emission factors for fuel burning in the industrial, commercial and institutional sectors.

Table 10: PM10 emission factors for industrial, commercial and institutional fuel combustion

\begin{tabular}{|l|l|l|}
\hline FUEL & UNITS & PM10 \\
\hline Coal & $\mathrm{kg} /$ tonne & 6.60 \\
\hline Coke & $\mathrm{kg} /$ tonne & 6.60 \\
\hline Diesel & $\mathrm{kg} /$ kilolitre & 0.96 \\
\hline Paraffin & $\mathrm{kg} /$ kilolitre & 0.24 \\
\hline Wood & $\mathrm{kg} /$ tonne & 2.63 \\
\hline LPG & $\mathrm{kg} / \mathrm{kilolitre}$ & 0.07 \\
\hline Waste & $\mathrm{kg} /$ tonne & 6.30 \\
\hline Natural gas & $\mathrm{kg} / 10^{3} \mathrm{~m}^{3}$ & 0.03 \\
\hline
\end{tabular}

Source: adapted from Scorgie \& Watson (2004)

Scorgie \& Watson (2004) also derived the following PM10 emission factors for household fuel combustion.

\section{Table 11: PM10 emission factors for household fuel combustion}




\begin{tabular}{|l|l|l|}
\hline FUEL & UNITS & PM10 \\
\hline Coal & $\mathrm{g} / \mathrm{kg}$ & 4.10 \\
\hline Paraffin & $\mathrm{g} / \mathrm{l}$ & 0.20 \\
\hline LPG & $\mathrm{g} / \mathrm{kg}$ & 0.07 \\
\hline Wood & $\mathrm{g} / \mathrm{kg}$ & 15.70 \\
\hline
\end{tabular}

Source: adapted from Scorgie \& Watson (2004)

On one hand, for interventions using the above fuels it is easy to compute their effectiveness in PM10 reduction by making use of the emission factors given in Tables 10 and 11. First, consider the displacement of wood used by households. The effect of displacing wood should be a reduction in PM10. The KAPS survey reported an average daily wood consumption by informal meat traders of $50 \mathrm{~kg}$ (KAPS 2008). Using the emission factors in Table 11, the differential impact of a switch from wood braais to gas braais is a reduction in PM10 of $15.63 \mathrm{~g}$ for every $1 \mathrm{~kg}$ reduction in wood used. On average each trader would contribute to a daily and weekly PM10 reduction of about $781.5 \mathrm{~g}$ and $5.470 \mathrm{~kg}$ respectively. ${ }^{17}$ Second, consider the displacement of burnt waste. We estimate that one black bag full of waste has an average mass of about $25 \mathrm{~kg}$. Therefore, a skip with a capacity of 72 black bags would have an estimated capacity of $1800 \mathrm{~kg}$. Providing an additional skip which is lifted twice a week means that at best, an estimated $3600 \mathrm{~kg}$ of household waste will be properly disposed of rather than burnt every week. The impact of the proper disposal is a reduction in PM10 of $6.30 \mathrm{~g}$ for every $1 \mathrm{~kg}$ reduction in burnt waste. Thus, the expected PM10 reduction from burnt waste per week would be $22.68 \mathrm{~kg} .{ }^{18}$

On the other hand, for those interventions which bring about PM10 reduction through elimination of windblown dust, an intricate modelling of the dispersion mechanisms of PM10 emissions would be called for. For instance, the main factors influencing traffic-generated dust emissions alone on unpaved roads include vehicle velocity, number of wheels per vehicle, particle size distribution, road surface moisture, tyre width, length of unpaved road, and traffic volume. Unfortunately, such modelling is beyond the scope of this study; in addition, dispersion modelling for the KAPS project is still ongoing and the current study could not benefit from those results. Table 12 shows the effectiveness measures for promoting the use of alternative, cleaner-burning energy sources (i.e. using gas braais) and providing additional refuse skips for household waste. The table also shows the lack of data on the effectiveness of planting windbreak trees and covering unpaved roads and walkways.

This is not a trivial reduction given that the airport and medical waste incineration were each estimated to emit about 3 tonnes of PM10 in 2004 (Scorgie \& Watson 2004). The number of informal meat traders in Khayelitsha is not known. Nevertheless, it is not expected that all meat traders could adopt gas braais in place of wood braais, because of concerns related to affordability, access, safety and security. However, for every 20 informal meat traders to adopt the gas braais, annual PM10 emissions would decrease by over five tonnes. (The focus groups during the survey stages included 20 informal meat traders.)

The Solid Waste Department asserts that there is a limit to the extent to which providing additional skips will reduce PM10 since there is not much additional household waste to collect, given the existing high wastemanagement service-delivery levels. 
Table 12: The effectiveness of the PM10 reduction interventions

\begin{tabular}{|l|l|}
\hline Intervention & Effectiveness \\
& (PM10 reduction) \\
\hline Planting of windbreak trees & $?$ \\
\hline Covering of unpaved roads and walkways & $?$ \\
\hline Promoting the use of alternative, cleaner-burning energy sources & $5.470 \mathrm{~kg} / \mathrm{braai} / \mathrm{week}$ \\
\hline Providing additional refuse skips for household waste & $22.68 \mathrm{~kg} / \mathrm{skip} / \mathrm{week}$ \\
\hline
\end{tabular}

Thus, as was pointed out earlier, the proposed interventions for reducing PM10 in Khayelitsha are not comparable, and evaluating their effectiveness is non-trivial. Despite the difficulties caused by the lack of objective data on the effectiveness of the various interventions, this section tries to give a cost-effectiveness ranking on the basis of perceptions of effectiveness. It starts from the realisation that pollution control is a long-term activity. It is therefore assumed that the objective of the current analysis is to guide the selection and ranking of the proposed interventions over a 20 -year time horizon. In order to do this, we pick the intervention that we think is the simplest in terms of implementation by the City and use it as the base category for comparison purposes.

On this basis, we pick the provision of additional skips as the base category, as it entails contracting (or possibly extending the current contracts of existing) private waste management service providers to do so. The provision of an additional skip will cost R900 per lift and two lifts per week are expected, i.e. a cost of R1 800 per week. If a decision were made to provide and service an additional skip for 20 years, it would cost R1 872000 , assuming that the price remained constant. (The assumption of a fixed price is not unrealistic, as the contract and payment can be made immediately, with the service provider being cushioned by the interest he or she can earn from invested prepayments.)

Now, for comparison we assume that an initial capital outlay of R1 872000 has been put forward for use by any of the other interventions. Firstly, tree-planting: as the cost of planting and maintaining a tree is between R2 000 and R4 460, it is possible to plant between 419 and 936 trees immediately, from the given capital outlay. Secondly, paving: as the cost of paving is $\mathrm{R} 280 / \mathrm{m}^{2}$, it is possible to pave $6685 \mathrm{~m}^{2}$ immediately, from the same capital outlay. Lastly, gas braais: as the gas braai equipment costs between R2 150 and R4 150 each, it is possible to supply between 451 and 870 gas braai sets from the given capital outlay.

Even though we do not have objective data on the effectiveness in PM10 reduction of all the proposed interventions, we use our perception of the effectiveness of the proposed interventions assuming a capital outlay of R1 872000 for each. The provision of 451 to 870 gas braai sets to informal traders in Khayelitsha is likely to have an immediate, significant impact on PM10 reduction. Given that the wood PM10 emission factor is $15.7 \mathrm{~kg} /$ tonne, displacing wood usage of $50 \mathrm{~kg}$ per day per informal trader by switching to gas should contribute significantly to PM10 reduction in Khayelitsha. The next most effective interventions are likely to be those which reduce dust. Planting 419 to 936 trees in a strategic formation is likely to reduce more windblown dust than would paving $6685 \mathrm{~m} 2$ of exposed areas. Lastly, provision of an additional 
skip for the duration of the planning horizon is expected to be the least effective. (We have ranked the 'gas braais' intervention ahead of provision of additional refuse skips despite the latter having a lower cost-effectiveness ratio; because in this case, many gas braais have more effectiveness than one skip.)

Therefore, based on our perception of the effectiveness of the proposed interventions, we can create an ordinal effectiveness measure of the proposed interventions in Table 13, where a higher value indicates greater effectiveness. It should be noted that with an ordinal measure, what matters are relative positions rather than actual magnitudes; therefore, the multiples of 1000 used here could have been any set of numbers, as long as the same ranking is applied to each line item.

Table 13: Perceived ordinal effectiveness of specified PM10 reduction interventions

\begin{tabular}{|l|l|l|}
\hline Intervention & $\begin{array}{l}\text { Quantity } \\
\text { (from budgeted R1 872 000) }\end{array}$ & Effectiveness \\
\hline Planting of windbreak trees & 419 to 936 trees & 3000 \\
\hline Covering of unpaved roads and walkways & $6685 \mathrm{~m}^{2}$ paving & 2000 \\
\hline Promoting the use of cleaner energy sources & 451 to 870 gas braais & 4000 \\
\hline Providing additional refuse skips for waste & 1 skip & 1000 \\
\hline
\end{tabular}

\section{Results and discussion}

Cost-effectiveness analysis provides some guidelines for selecting and ranking proposed alternative interventions on the basis of their costs and impacts on PM10 reduction. Given the above ordinal ranking of effectiveness and the fact that the cost of the above interventions is the same, it is possible to compute specific cost-effectiveness ratios. The cost-effectiveness ratios are computed by dividing the costs of each alternative by the measure of its effectiveness. Costeffectiveness analysis in this case gives preference to those interventions with the lowest cost of achieving PM10 reductions. The cost-effectiveness ranking (in descending order) is as follows: (1) providing gas braai sets to meat traders; (2) planting windbreak trees; (3) paving exposed areas; and (4) providing extra refuse skips. This information is also provided in table 14.

Table 14: Cost-effectiveness analysis of specified PM10 reduction interventions

\begin{tabular}{|l|l|l|l|l|}
\hline Intervention & Cost & Effectiveness & $\begin{array}{l}\text { Cost- } \\
\text { effectiveness } \\
\text { ratio }\end{array}$ & $\begin{array}{l}\text { Cost- } \\
\text { effectiveness } \\
\text { ranking }\end{array}$ \\
\hline
\end{tabular}




\begin{tabular}{|l|l|l|l|}
\hline $\begin{array}{l}\text { Planting of } 419 \text { to 936R1 872000 } \\
\text { windbreak trees }\end{array}$ & 3000 & 624 & 2 \\
\hline $\begin{array}{l}\text { Covering of } 6685 \mathrm{~m}^{2} \mathrm{R} 1872000 \\
\text { unpaved roads and walkways }\end{array}$ & 2000 & 936 & 3 \\
\hline $\begin{array}{l}\text { Promoting the use of } 451 \text { to R1 } 872000 \\
870 \text { gas braais }\end{array}$ & 4000 & 468 & 1 \\
\hline $\begin{array}{l}\text { Providing one additionalR1 } 872000 \\
\text { refuse skip for waste }\end{array}$ & 1000 & 1872 & 4 \\
\hline
\end{tabular}

As indicated earlier, cost-effectiveness analysis only provides some guidelines for selecting and ranking proposed alternative interventions on the basis of their costs and impacts. Ultimately, the actual selection and ranking of alternatives would have to take into account many other factors such as socioeconomic, implementation and enforcement issues - for example, planting windbreak trees results in a reduction of carbon dioxide in addition to reducing PM10; this means that it may be possible to link this intervention to climate change initiatives, thus opening up a wide range of potential funding opportunities.

\section{Conclusion and recommendation}

The average PM10 levels in Khayelitsha are unusually high and are estimated to be $70 \%$ above those of the Cape Town CBD nearby (KAPS 2008). High PM10 levels are detrimental to people's health, productivity and amenity values. The KAPS project was implemented partly to provide an understanding of the factors behind the observed high levels of PM10 in Khayelitsha. The current study aimed to give cost-effectiveness rankings of feasible interventions for reducing PM10 levels in Khayelitsha. Given the huge disparity in the scales of these interventions and the general lack of objective data on their effectiveness, the study used the scale for each intervention that was compatible with a capital outlay of R1 872000 - the amount needed to provide one additional refuse skip over a 20 -year planning horizon.

In cash terms, the following are cost equivalents: planting between 419 and 936 trees in a strategic formation to reduce windblown dust; paving $6685 \mathrm{~m}^{2}$ of exposed areas; providing between 451 and 870 gas braai sets to informal meat traders to replace their wood-fired braais; and providing one additional refuse skip for a 20-year planning horizon. Using our perception of the effectiveness of the above interventions in reducing PM10 pollution or its precursors, the interventions were ranked in descending order of effectiveness as follows: (1) providing gas braai sets to meat traders; (2) planting windbreak trees; (3) paving exposed areas; and (4) providing extra refuse skips. Providing gas braai sets to the meat traders of Khayelitsha will significantly reduce the PM10 levels, but also contribute to the sustained livelihoods of some of the poor households.

Thus, despite the difficulties caused by the lack of objective data on the effectiveness of the various interventions, this study has given some guidance on how to select and rank the proposed interventions, primarily making use of cost data and perceptions on effectiveness. It 
should be reiterated that cost-effectiveness analysis only provides guidelines for selecting and ranking proposed alternative interventions on the basis of their costs and impacts. In addition, other relevant constraints such as socioeconomic, implementation and enforcement issues must be taken into account when choosing between the alternatives. For example, planting windbreak trees may be chosen ahead of the other options because of its linkage to climate change initiatives, which could open up a wide range of potential funding opportunities.

\section{References}

Benson, Sally (2008). (personal communication); Air Quality Monitoring, Scientific Services, City of Cape Town.

Boardman, A.E., Greenberg, D.H., Vining, A.R. and Weimar, D.L. (2006). Cost-Benefit Analysis: Concepts and Practice, $3^{\text {rd }}$ Edition. Pearson-Prentice-Hall, New Jersey.

Burgess, Claire (2008). (personal communication); Vela VKE Engineering (Pty) Ltd, Contractor of the City of Cape Town on the Klipfontein Non-Motorised Transport Route.

City of Cape Town (CoCT) (2005a). 'A Socio-Economic Profile of Ward 91 (Khayelitsha) looking at the Economic and Human Development Department's programmes and projects in 2005/06', Economic and Human Development Department, August 2005.

City of Cape Town (CoCT) (2005b). 'A Socio-Economic Profile of Ward 92 (Khayelitsha, Site B) looking at the Economic and Human Development Department's programmes and projects in 2005/06', Economic and Human Development Department, August 2005.

City of Cape Town (CoCT) (2006a). 'A Socio-Economic Profile of Ward 87 (Khayelitsha) looking at the Economic and Human Development Department's programmes and projects in 2005/06', Economic and Human Development Department, January 2006.

City of Cape Town (CoCT) (2006b). 'A Socio-Economic Profile of Ward 88 (Heinz Park, New Woodlands, Philippi) looking at the Economic and Human Development Department's programmes and projects in 2005/06', Economic and Human Development Department, January 2006.

City of Cape Town (CoCT) (2006c). 'A Socio-Economic Profile of Ward 89 (Khayelitsha) looking at the Economic and Human Development Department's programmes and projects in 2005/06', Economic and Human Development Department, January 2006.

City of Cape Town (CoCT) (2006d). 'A Socio-Economic Profile of Ward 90 (Khayelitsha, Site C) looking at the Economic and Human Development Department's programmes and projects in 2005/06', Economic and Human Development Department, January 2006.

Coetzee, Barry (2008). (personal communication); Manager: IWM Strategy, Policy and By-laws; Solid Waste Planning, City of Cape Town.

Escobedo, F.J., Wagner, J.E., Nowak, D.J., Luz de la Maza, C., Rodriguez, M. and Crane, D.E. (2008). Analyzing the cost effectiveness of Santiago, Chile's policy of using urban forests 
to improve air quality. Journal of Environmental Management, Volume 86, Issue 1: 14857.

Grønskei, K.E., Gram, F., Hagen, L.O., Larssen, S., Jansen, H., Olsthoorn, X. and others. (1996a). URBAIR Urban Air Quality Management Strategy in Asia: Jakarta Report. Washington, DC: World Bank.

Grønskei, K.E., Gram, F., Hagen, L.O., Larssen, S., Jansen, H., Olsthoorn, X. and others. (1996b). URBAIR Urban Air Quality Management Strategy in Asia: Kathmandu Valley Report. Washington, DC: World Bank.

Horn, Peter (2008). (personal communication); Area Cleaning Branch; Solid Waste Planning, City of Cape Town.

KAPS (2008). Khayelitsha Air Pollution Strategy Project (KAPS) Report. Directorate: City Health, City of Cape Town, Cape Town, South Africa.

Kjellström, T., Lodh, M., McMichael, T., Ranmuthugala, G., Shrestha, R. and Kingsland, S. (2006). 'Air and Water Pollution: Burden and Strategies for Control.' Disease Control Priorities in Developing Countries (2nd Edition). New York: Oxford University Press. DOI: 10.1596/978-0-821-36179-5/Chpt-43: 817-32

Krupnick, A.J. and Portney, P.R. (1991). Controlling urban air pollution: A benefit-cost assessment. Science 1991; 252: 522-8.

Larssen, S., Gram, F., Hagen, L.O., Jansen, H., Olsthoorn, X., Aundhe, R.V. and Joglekar, U. (1996a). URBAIR Urban Air Quality Management Strategy in Asia: Greater Mumbai Report. Washington, DC: World Bank.

Larssen, S., Gram, F., Hagen, L.O., Jansen, H., Olsthoorn, X., Lesaca, R. and others. (1996b). URBAIR Urban Air Quality Management Strategy in Asia: Metro Manila Report. Washington, DC: World Bank.

Leiman, A., Standish, B., Boting, A. and Van Zyl, H. (2007). Reducing the healthcare costs of urban air pollution: The South African experience. Journal of Environmental Management, Volume 84(1): 27-37.

Mathee, A. and Von Schirnding, Y.E.R. (1996). Living conditions and environmental health status in two informal settlements in the Cape Peninsula. Development Southern Africa, 13(1): 129-39.

Maverick 358 cc. (2006). The Population Register Update: Khayelitsha 2005, Sub-Directorate Population Development, Research and Population Directorate, Department of Social Services and Poverty Alleviation, April 2006.

Médecins Sans Frontières (2010). Providing HIV/TB Care at The Primary Health Care Level, Khayelitsha Annual Activity Report 2008-2009, co-produced by Western Cape Province Department of Health, City of Cape Town Department of Health and University of Cape Town Centre for Infectious Disease Epidemiology and Research, February 2010. http://www.msf.org.za/Docs/Khayelitsha/Khayelitsha_Report_2008-2009.pdf (Accessed 7 November 2010). 
McPherson, E.G., Scott, K.I. and Simpson, J.R. (1998). Estimating cost effectiveness of residential yard trees for improving air quality in Sacramento, California using existing models. Atmospheric Environment 32: 75-84.

McPherson, E.G., Simpson, J.R., Pepper, P.J. and Xiao, Q. (1999). Benefit-cost analysis of Modesto's municipal urban forest. Journal of Arboriculture 25 (5): 235-248.

Moolgavkar, S.H. (2000). Air Pollution and Daily Mortality in Three U.S. Countries; Environ. Health Perspect., 50: 1287-98.

Mrubata, M., Kruger, T. and Moepye, K. (2008). 'Implementation Scoping with Khayelitsha Meat Traders: Field Visit 17 March 2008'. Report to the City of Cape Town submitted by GTZ Probec.

Ndingaye, Xoliswa Zandile. (2005). 'An Evaluation of the Effects of Poverty in Khayelitsha: a Case Study of Site C'. Masters Thesis, Institute for Social Development, Bellville, South Africa: University of the Western Cape.

Nowak, D., Cardelino, C.A., Rao, S.T. and Taha, H. (1998). Discussion: estimating cost effectiveness of residential yard trees for improving air quality in Sacramento, California using existing models. Atmospheric Environment 32 (14/15): 2709-11.

O’Ryan, R.E. (1993). Cost effective policies to improve urban air quality in developing countries: case study for Santiago, Chile. Ph.D. Dissertation, University of California, Berkeley.

Perman, R., Ma, Y., McGilvary, J. and Common, M. (2003). Natural Resource and Environmental Economics, $3^{\text {rd }}$ Edition, Prentice Hall, UK.

Schwartz, J. (1994). Air Pollution and Daily Mortality; A Review and Meta-Analysis; Environ. Res., 64: $36-52$.

Scorgie, Y. and Watson, R. (2004). Updated air quality situation assessment for the City of Cape Town. Report done on behalf of: City of Cape Town, Report No. APP/04/CCT02 .

Shah, J., Nagpal, T. and Brandon, C. (eds.) (1997). Urban Air Quality Management Strategy in Asia: Guidebook. Washington, DC: World Bank.

Schoeman, Robyn-Anne (2008). (personal communication); Vela VKE Engineering (Pty) Ltd, Contractor of the City of Cape Town on the Klipfontein Non-Motorized Transport Route.

StatsSA (2007). Community Survey 2007: Statistical Release. Statistics South Africa, Pretoria, South Africa.

Tukushe, Elias (2008). (personal communication); Universal Access and Non-Motorized Transport, Transport Planning, City of Cape Town.

U.S. Environmental Protection Agency (US EPA) (2006). An Analysis of the Cost-effectiveness of Reducing Particulate Matter Emissions from Heavy Duty Diesel Engines through

$T D, 6(2)$, December 2010, pp. 333-358. 
Retrofits, EPA420-S-06-002, Office of Transportation and Air Quality, Research Triangle Park, NC.

Voorhees, A.S., Sakai, R., Araki, S., Sato, H. and Otsu, A. (2001). 'Cost-benefit analysis methods for assessing air pollution control programs in urban environments - a review', Environmental Health and Preventive Medicine 6:(July): 63-73.

Wicking-Baird, M.C., De Villiers, M.G. and Dutkiewicz, R.K. (1997). Cape Town Brown Haze Study, Report No. Gen 192, Energy Research Institute, September 1997.

Wilson, W.W. and Suh, H.H. (1997). 'Fine Particles and Coarse Particles: Concentration Relationships Relevant to Epidemiologic Studies'; J. Air \& Waste Manage. Assoc., 47: 1238-49. 